\title{
Implementation of secondary reconstructions of flat-panel volume computed tomography (fpVCT) and otological planning software for anatomically based cochlear implantation
}

\author{
Franz-Tassilo Müller-Graff ${ }^{1}$. Lukas Ilgen ${ }^{1}$. Philipp Schendzielorz ${ }^{1}$. Johannes Voelker ${ }^{1}$. Johannes Taeger ${ }^{1}$. \\ Anja Kurz ${ }^{1} \cdot$ Rudolf Hagen $^{1} \cdot$ Tilmann Neun $^{2} \cdot$ Kristen Rak $^{1}$ (D)
}

Received: 5 March 2021 / Accepted: 29 May 2021 / Published online: 8 June 2021

(C) The Author(s) 2021

\begin{abstract}
Purpose For further improvements in cochlear implantation, the measurement of the cochlear duct length (CDL) and the determination of the electrode contact position (ECP) are increasingly in the focus of clinical research. Usually, these items were investigated by multislice computed tomography (MSCT). The determination of ECP was only possible by research programs so far. Flat-panel volume computed tomography (fpVCT) and its secondary reconstructions (fpVCT $\mathrm{SECO}_{\text {) allow }}$ for high spatial resolution for the visualization of the temporal bone structures. Using a newly developed surgical planning software that enables the evaluation of CDL and the determination of postoperative ECP, this study aimed to investigate the combination of fpVCT and otological planning software to improve the implementation of an anatomically based cochlear implantation.

Methods Cochlear measurements were performed utilizing surgical planning software in imaging data (MSCT, fpVCT and $\mathrm{fpVCT}_{\mathrm{SECO}}$ ) of patients with and without implanted electrodes.

Results Measurement of the CDL by the use of an otological planning software was highly reliable using fpVCT SECO $_{\text {with a }}$ lower variance between the respective measurements compared to MSCT. The determination of the inter-electrode-distance (IED) between the ECP was improved in $\mathrm{fpVCT}_{\mathrm{SECO}}$ compared to MSCT.

Conclusion The combination of $\mathrm{fpVCT}_{\mathrm{SECO}}$ and otological planning software permits a simplified and more reliable analysis of the cochlea in the pre- and postoperative setting. The combination of both systems will enable further progress in the development of an anatomically based cochlear implantation.
\end{abstract}

Keywords Cochlear duct length $\cdot$ Cochlear planning software $\cdot \mathrm{fpVCT} \cdot$ Secondary reconstruction $\cdot$ MSCT $\cdot$ Interelectrode-distance

\section{Introduction}

In cochlear implantation, best possible speech perception is desirable. Along with several other favourable prognostic factors in adults such as the motivation of the patient,

\section{Kristen Rak}

Rak_K@ukw.de

1 Department of Oto-Rhino-Laryngology, Plastic, Aesthetic and Reconstructive Head and Neck Surgery and the Comprehensive Hearing Center, University of Wuerzburg, Josef-Schneider-Strasse 11, 97080 Wuerzburg, Germany

2 Insitute for Diagnostic and Interventional Neuroradiology, University of Wuerzburg, Bavaria, Germany medical history with occurrence of postlingual hearing loss and a short period of deafness, it is assumed that best speech perception can be reached by the correct electrode selection and an appropriate cochlear coverage [1-4]. Therefore, it is necessary to have sufficient data on the cochlear anatomy preoperatively, especially on the cochlear duct length (CDL). In recent years, new imaging technologies, models and formulas have been developed to measure the CDL [5-14]. Most of these studies were based on measurements of the CDL by Escudé in 2006 [5]. Most frequently, MSCT [5, 12] or cone-beam CT [8-10, 13, 14] have been used. In some studies, results were compared to more precise imaging, like micro-CT $[9,11,13]$ or synchrotron radiation phase-contrast imaging $[6,7]$ as a reference method. 
The flat-panel volume computed tomography (fpVCT) system has an innovative design which allows imaging of entire organs in one axial acquisition with an ultra-high spatial resolution [15]. Initial studies found superior image quality of the fine osseous temporal bone structures than in currently available MSCT scanners [16]. The first application of fpVCT in patients revealed a proper resolution regarding the critical structures for cochlear implantation [17]. Other studies first showed a significantly higher overall image quality compared to MSCT and a reduction of the effective dose of approximately $40 \%$ compared to 64 -section- [18] and 128-section-MSCT [19]. Further advantages of fpVCT are portability-enabling the intraoperative use and reduced metallic artifacts, allowing postoperative position analyses, and more accurate frequency mapping of the electrode contacts [20-22]. As reported by Pearl et al. fpVCT offers the possibility to enhance image quality by secondary reconstructions ( $\mathrm{fpVCT}_{\mathrm{SECO}}$ ) [23], which can reach the same accuracy in measuring the CDL compared to experimental Micro-CT [24].

A specially designed software for otological surgical planning has been used, inter alia, to evaluate the possibility of facial nerve segmentation for otological training [25] and surgical planning of cochlear implantation in cases with post-meningitis ossification [26]. The clinical applicability of the software, in particular an angular insertion depth prediction for preoperative electrode selection has been demonstrated [27]. In various recently published studies, the CDL was also measured with this software, using MSCT and MRI [28-30]. They revealed low inter- as well as intraobserver variability and reliability [28, 29]. So far, evaluation of pre and postoperative clinical cochlear data created with fpVCT using the otological software has not been performed.

In the present study, different aspects should be investigated. Firstly, does the application of the fpVCT or $\mathrm{fpVCT}_{\mathrm{SECO}}$ facilitate the preoperative measurements of the CDL in comparison to MSCT in the otological planning software, secondly, is it possible herewith to have a reliable measure of the postoperative $\mathrm{CDL}$ with $\mathrm{fpVCT}$ or $\mathrm{fpVCT}_{\mathrm{SECO}}$ and thirdly, is there a difference in estimating the relative position of the electrode contacts in the comparison between fpVCT, $\mathrm{fpVCT}_{\mathrm{SECO}}$ and MSCT?

\section{Methods}

\section{Subjects and groups}

In this retrospective single-center study, 30 patients from two cohorts were included, who were divided into three groups as depicted in Table 1.

In one cohort, 20 patients were included who were implanted with a MED-EL FLEX ${ }^{28}$ electrode $(28 \mathrm{~mm}$ electrode with 12 single contacts each $2.1 \mathrm{~mm}$ apart). All cochlear implantations were performed by experienced otosurgeons (KR, RH). For all patients, this was the first implanted ear. Mean age of the patients was 64 years (standard deviation (SD): 14.9 years). Surgery was performed for 12 patients on the right and for eight on the left ear. Every patient had a preoperative MSCT of the temporal bone and a postoperative fpVCT for position control of the implanted electrode. In addition, $\mathrm{fpVCT}_{\mathrm{SECO}}$ was performed using the data of the fpVCT. Since radiological examinations of the patients include both temporal bones, different investigations with the three imaging modalities could be performed: in non-implanted ears (Group 1) and in preoperative nonimplanted and postoperative implanted ears (Group 2).

Further images were evaluated in a second cohort of 10 patients, in which a MSCT and an fpVCT of an implanted ear was available. Consequently, the comparison of the three imaging modalities in implanted ears (Group 3) was possible. The mean age of this cohort was 57 years (SD: 21.2 years). Four subjects received their implant on the right side, six on the left side.

The retrospective anonymized study was conducted in concordance with local guidelines and principles of the Declaration of Helsinki and Good Clinical Practice and was approved by the local ethics committee at the University of Wuerzburg (2019020401).

\section{Imaging}

FpVCT scans were performed using an angiographic unit (Axiom Artis; Siemens Healthcare AG, Erlangen, Germany) with commercially available software (Syngo DynaCT, Siemens).

The MSCT datasets were acquired using a SOMATOM Definition AS + (Siemens) with commercially available
Table 1 Data of the cohorts of patients used in this study

\begin{tabular}{llllllll}
\hline Cohort & Patients & Age & Implanted side & Group & Image modality & \\
\cline { 6 - 7 } & & & & & & MSCT & $\mathrm{fpVCT/fpVCT}$ SECO \\
\hline I & 20 & 64 & 12 Right & 8 Left & 1 & Non-implanted & Non-implanted \\
II & 10 & 57 & 4 Right & 6 Left & 3 & Implanted & Implanted \\
\hline
\end{tabular}


software (Syngo CT, Siemens). The standard application (inner ear high-resolution program) was applied using the following parameters: tube current $=38 \mathrm{~mA}$; tube voltage $=120 \mathrm{kV}$; collimation $=0.6 \mathrm{~mm}$; pitch $=0.55$; slice thickness $=600 \mu \mathrm{m}$.

The fpVCT datasets were acquired using the following parameters: $20 \mathrm{~s} \mathrm{DCT} \mathrm{Head} \mathrm{protocol;} \mathrm{tube} \mathrm{current}=21 \mathrm{~mA}$; tube voltage $=109 \mathrm{kV}$; rotation angle $=200$ degree; pulse length $=3.5 \mathrm{~ms}$; frame angulation step $=0.5$ degree/frame; slice thickness $=466 \mu \mathrm{m}$.

From these datasets, fpVCT $\mathrm{SECO}_{\mathrm{SEO}}$ were designed according to the findings of Pearl et al. [23] using the following settings: $512 \times 512$ section matrix; HU kernel types; sharp image characteristics; slice thickness $=99 \mu \mathrm{m}$. Visual comparison of different imaging modalities and settings is presented in Fig. 1A-F.

\section{Measurement of cochlear parameters and calculating $\mathrm{CDL}_{\mathrm{OC}}$}

To determine pre- and postoperative cochlear parameters, OTOPLAN ${ }^{\circledR}$ software (CAScination AG (Bern, Switzerland) in cooperation with MED-EL (Innsbruck, Austria), version 2) was used. The data sets were converted to the DICOM standard by the PACS network of the hospital and transferred anonymously to the software using a memory stick. In all images initially, the coronal oblique view, typically referred to as "Cochlear View" [31, 32], was created by 3-dimensionally rotating against the axial, sagittal and coronal axis (Fig. 1). After attempting to receive the most optimized view, the cochlear diameter (A) and width (B) were measured. Both, the process of orientation and landmark selection, were carried out in two test series with an interval of two weeks by one medical examiner, who is trained as an ENT-specialist and is very experienced in the evaluation of cochlear imaging. Patient's data were anonymized and the order of the evaluation of both the imaging modality as well as the temporal bones was randomized. The cochlear A-value is defined as a straight line from the round window, passing the modiolus, to the furthest point on the opposite wall of the cochlea. The cochlear B-value is the straight line connecting the two opposite lateral walls of the cochlea, perpendicular to the cochlear diameter passing through the modiolus. Visualization of the parameters in the different body axes is shown in Fig. 2A-C. From these data, the $\mathrm{CDL}$ of the organ of Corti $\left(\mathrm{CDL}_{\mathrm{OC}}\right)$ was calculated from the

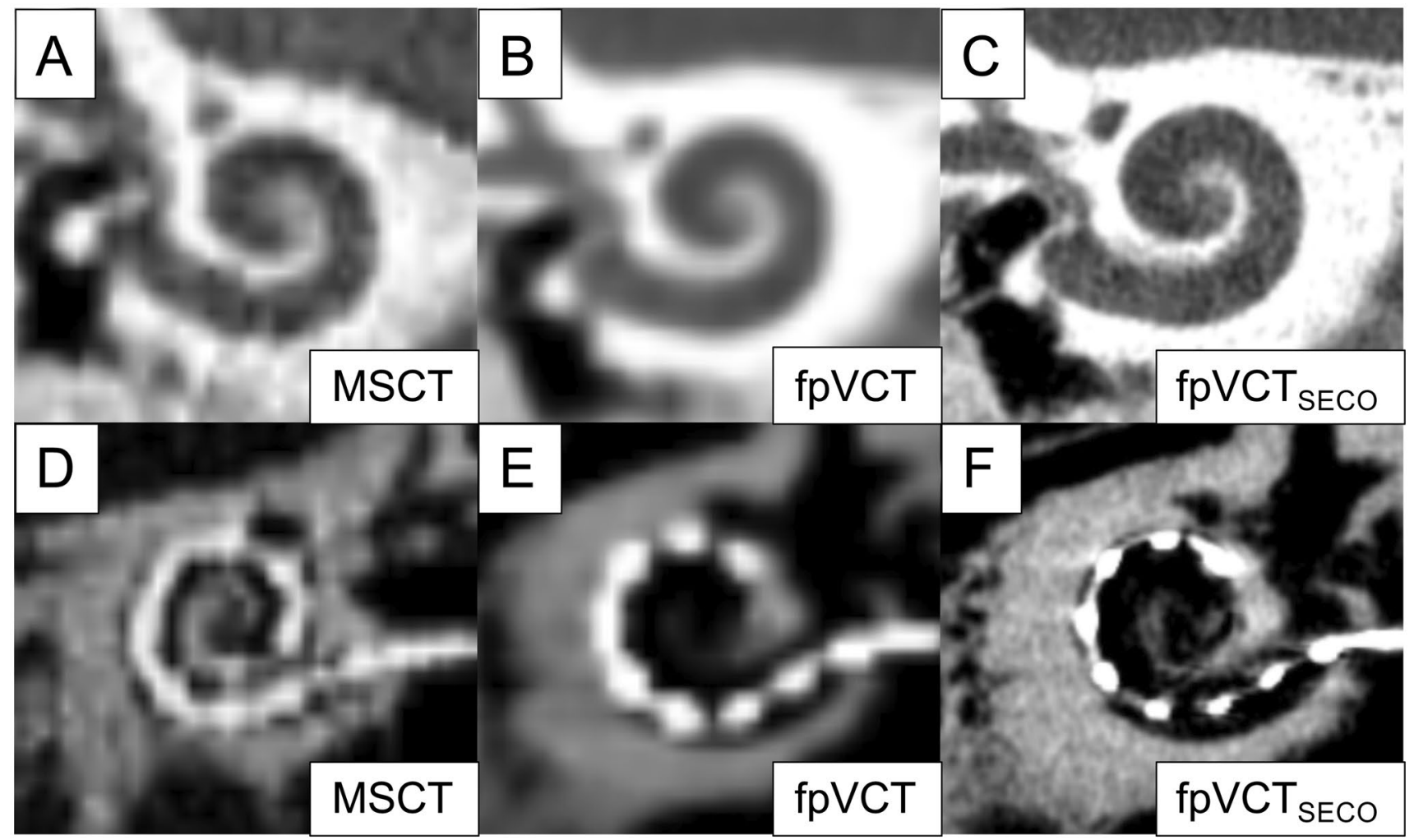

Fig. 1 "Cochlear view" of different imaging modalities and settings. Representative image of MSCT $(600 \mu \mathrm{m})$ is shown in panel (A), display of fpVCT $(466 \mu \mathrm{m})$ in panel $(\mathbf{B})$. Image of fpVCT $\mathrm{SECO}_{\text {SEO }}(99 \mu \mathrm{m})$ is presented in panel $(\mathbf{C})$. Respectively, panels $(\mathbf{D}-\mathbf{F})$ demonstrate the
"Cochlear View" [31] with an implanted electrode. MSCT: multislice computed tomography, fpVCT: flat-panel volume computer-tomography, fp $\mathrm{VCT}_{\mathrm{SECO}}$ : fpVCT secondary reconstruction 


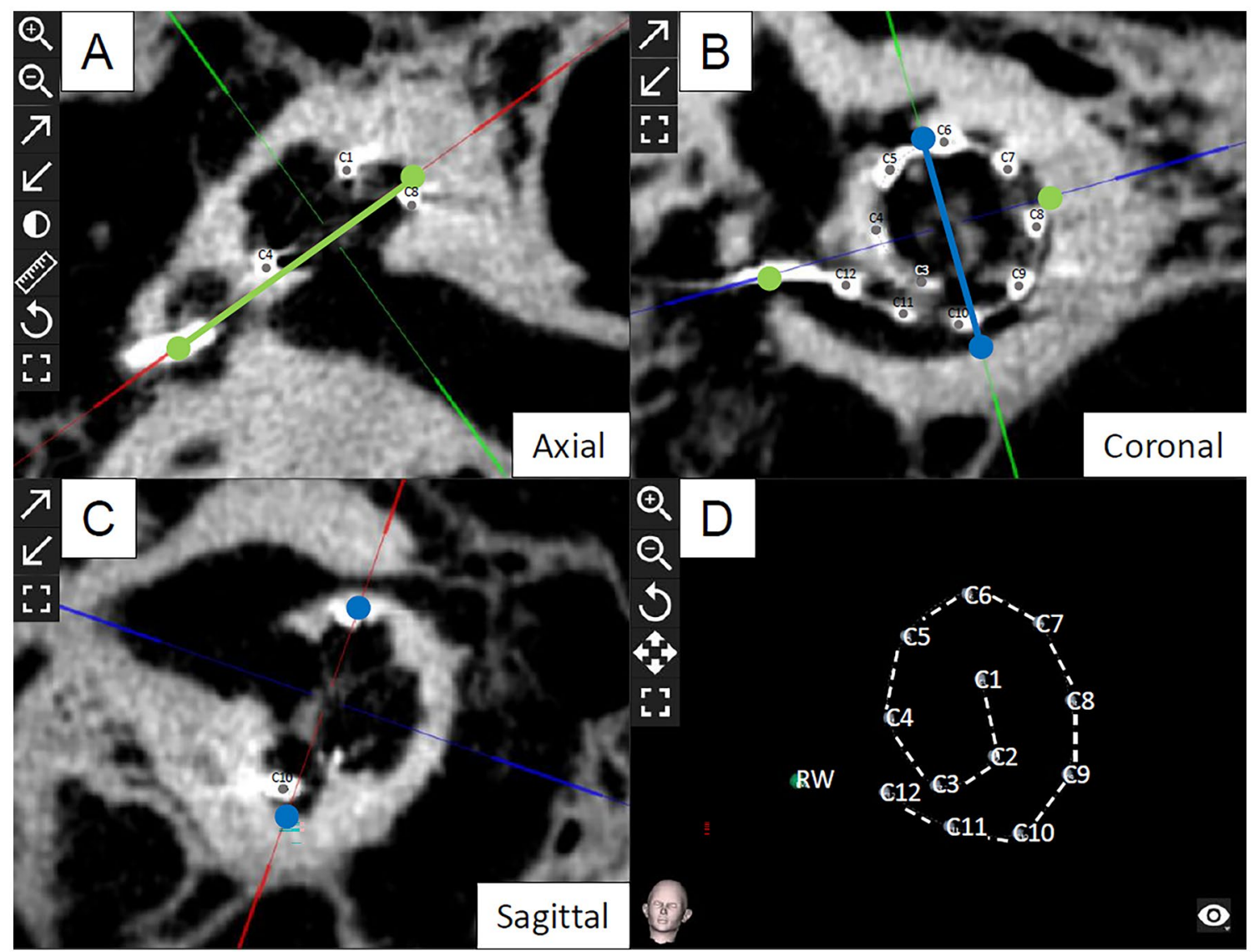

Fig. 2 Evaluation of cochlear parameters. Visualization of the cochlear parameters and the electrode contacts in the different body axes using $\mathrm{fpVCT}_{\mathrm{SECO}}$ in the otological planning software. The "axial view" is shown in panel (A), the "coronal", known as the "Cochlear View" [32] in panel (B) and the "sagittal view" in panel (C). Three-

otological software using Eq. (1), which has been originally described as the "elliptic circular approximation" [9]. Since the OC does not start at the center of the round window but reaches into the cochlear base, the equation in the software version used herein has been supplemented by the length of this so-called hook region of $1.58 \mathrm{~mm}$ as follows: dimensional display of the inserted implant electrodes after identifying them in the three-body axes is shown in panel (D). Diameter A is shown as green fiducials and line, width $\mathrm{B}$, respectively, as blue fiducials and line. From these data, $\mathrm{CDL}_{\mathrm{OC}}$ was calculated. $\mathrm{C} 1-12$ : Electrode contacts. $R W$ Round window

$\mathrm{CDL}_{\mathrm{OC}}=\left(1.71 \times\left(1.18 \times\left(A_{\mathrm{OC}}\right)+2.69 \times B_{\mathrm{OC}}\right)-\sqrt{\left(0.72 \times A_{\mathrm{OC}} \times B_{\mathrm{OC}}\right)} \times 0.18\right)+1.58$

\section{Determination of electrode contact position}

The electrode contact position (ECP) of the electrodes was determined to perform postoperative position control. Since all patients received a device with 12 electrodes, 12 fiducials were, respectively, placed by rotating through the 3D-illustrated "Cochlear View" [31]. The fiducials were placed as precisely as possible at the center of each electrode contact of the three body axes (Fig. 2A-C). From these data the otological planning software calculated the insertion depth in $\mathrm{mm}$ for every single electrode. For statistical analysis, the distances between every single electrode (inter-electrode distance, IED) were extracted. The entire electrode array can

be seen after these maneuvers and rotated in every direction in a three-dimensional display, as seen in Fig. 2D.

\section{Statistics}

Before parametrical analyses were conducted, the normal distribution of all data series was confirmed by Kolmogorov-Smirnov and Shapiro-Wilk test. As a requirement for paired $t$-test, normal distribution of the differences between 
both paired groups was also checked. The paired $t$-test was used for reference comparison between the two measurement series of the particular imaging modalities. Differences with a p-value of less than 0.05 were considered to be statistically significant. For evaluation of the differences of the absolute mean values of the $\mathrm{CDL}_{\mathrm{OC}}$ in the three modalities and settings, one-way repeated measures analysis of variance (ANOVA) was applied. When the data were not normally distributed, the Friedman-Test was used.

Intraclass correlation (ICC) was performed for evaluating intraobserver variability in each modality and setting within all test series. Based on the publication of Wirtz et al., a two-way mixed model was performed, and single measure values of ICC were used [33]. ICC was tested for absolute agreement. As described by Cicchetti et al., ICC values were interpreted by applying the following scale: unacceptable (ICC $<0.4)$, fair $(0.4 \leq \mathrm{ICC}<0.6)$, good $(0.6 \leq \mathrm{ICC}<0.75)$ and excellent $(0.75 \leq$ ICC $)$ [34]. The associated Cronbach's alpha (CA) was calculated according to the following scale: unacceptable $(\alpha<0.7)$, fair $(0.7 \leq \alpha<0.8)$, good $(0.8 \leq \alpha<0.9)$ and excellent $(0.9 \leq \alpha)$ [34]. For ICC and CA only significant results were considered.

According to Koch et al., a clinically acceptable margin of divergence of $\pm 1.5 \mathrm{~mm}$ for $\mathrm{CDL}_{\mathrm{OC}}$ was assumed [7]. With a recalculation from the same study, the clinically acceptable variance of $\pm 0.09 \mathrm{~mm}$ for IED was derived.

Statistical analyses and creating diagrams were performed by GraphPad Prism (Version 8.4.0, San Diego, California, USA), as well as IBM SPSS Statistics (Version 25.0.0.0; IBM Corporation, Armonk, New York USA). Data are presented in bar charts and Bland-Altman-Plots.

\section{Results}

\section{Population parameters}

All parameters of the measurements carried out, including mean values, ranges, SD, 95\%-confidence intervals (CI), ICC, CA and $t$-Test for both cohorts, are depicted in Table 2 .

\section{Group 1: determination of $\mathrm{CDL}_{\mathrm{OC}}$ in non-implanted ears by MSCT, fpVCT and fpVCT}

$\mathrm{CDL}_{\mathrm{OC}}$ were measured in non-implanted ears. The mean value for the length of the $\mathrm{CDL}_{\mathrm{OC}}$ were $34.55 \mathrm{~mm}$ (range: 31.20-6.95 mm, SD: $1.60 \mathrm{~mm}$ ) measured with MSCT. For fpVCT, it was $34.63 \mathrm{~mm}$ (range: $31.55-37.60 \mathrm{~mm}$, SD: $1.47 \mathrm{~mm}$ ) and for fpVCT $\mathrm{SECO}, 35.84 \mathrm{~mm}$ (range: $32.95-38.45$,
SD: $1.36 \mathrm{~mm}$ ) were determined (Fig. 3A). All values measured by fpVCT $\mathrm{SECO}_{\mathrm{SEO}}$ differed significantly from those evaluated using MSCT and fpVCT $(p<0.001)$. There were no significant differences in the measurements between MSCT and fpVCT.

When examining $\mathrm{CDL}_{\mathrm{OC}}$, there was a significant difference within the two test series using $\operatorname{MSCT}(p=0.0011)$ and fpVCT $(p=0.0297)$, but not applying fpVCT $\mathrm{SECO}_{\text {. ICC were }}$ consistently categorized as excellent for all imaging modalities. The lower limits of the CI were unacceptable (MSCT), fair (fpVCT), and excellent ( $\left.\mathrm{fpVCT}_{\mathrm{SECO}}\right)$. CA was classified as excellent for MSCT and fpVCT $\mathrm{SECO}_{\mathrm{SE}}$, and as good for fpVCT (Table 2).

Considering corresponding Bland-Altman-Plots for $\mathrm{CDL}_{\mathrm{OC}}$, which demonstrate clinically acceptable values, MSCT had four errors (Fig. 3B). Measurements with fpVCT showed two deviations (Fig. 3C) and assessing fpVCT $\mathrm{SECO}_{\mathrm{SE}}$, there were no divergencies (Fig. 3D).

Overall, $\mathrm{fpVCT}_{\mathrm{SECO}}$ was categorized as excellent and had no clinically unacceptable deviations when measuring cochlear parameters in cochleae without an inserted electrode.

\section{Group 2: measurements of $\mathrm{CDL}_{\mathrm{OC}}$ by using non-implanted preoperative MSCT and postoperative fpVCT and fpVCT $\mathrm{SECO}_{\text {. }}$ with an inserted electrode}

To evaluate whether it is possible to have a reliable postoperative measurement with $\mathrm{fpVCT}$ or $\mathrm{fpVCT}_{\mathrm{SECO}}$ despite the inserted electrode, $\mathrm{CDL}_{\mathrm{OC}}$ were measured pre- and postoperatively. The mean values for the length of the $\mathrm{CDL}_{\mathrm{OC}}$ were $34.29 \mathrm{~mm}$ (range: $30.50-37.15 \mathrm{~mm}, \mathrm{SD}: 1.81 \mathrm{~mm}$ ) measured with preoperative MSCT. For postoperative fpVCT, it was $36.43 \mathrm{~mm}$ (range: $33.55-39.30 \mathrm{~mm}$, SD: $1.67 \mathrm{~mm}$ ) and for postoperative fpVCT $\mathrm{SECO}_{\text {CO }} 36.18 \mathrm{~mm}$ (range: $32.90-39.60$, SD: $1.75 \mathrm{~mm}$ ) (Fig. 4A). The values measured in MSCT differed significantly from those evaluated with $\mathrm{fpVCT}$ and $\mathrm{fpVCT}_{\text {SECO }}\left(p<0.001\right.$ for $\left.\mathrm{CDL}_{\mathrm{OC}}\right)$. Between fpVCT and $\mathrm{fpVCT}_{\mathrm{SECO}}$ measurements, no significant differences were observed.

Regarding $\mathrm{CDL}_{\mathrm{OC}}$, there was a significant difference within the test series for MSCT $(p=0.0077)$, but not for fpVCT and $\mathrm{fpVCT}_{\mathrm{SECO}}$. ICC and CA were consistently rated to be excellent. The lower limit of the $\mathrm{CI}$ was only excellent for fpVCT $_{\mathrm{SECO}}$ and fair for MSCT and fpVCT (Table 2). Summarising, using $\mathrm{fpVCT}_{\mathrm{SECO}}$ to evaluate $\mathrm{CDL}_{\mathrm{OC}}$ postoperatively was exclusively excellent.

In the corresponding Bland-Altman-Plots, using MSCT produced two clinically unacceptable deviations for $\mathrm{CDL}_{\mathrm{OC}}$ (Fig. 4B). Measurements with fpVCT showed four aberrations

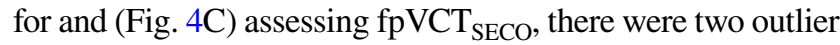
(Fig. 4D). 
Table 2 Analysis of non-implanted and implanted ears

\begin{tabular}{|c|c|c|c|c|}
\hline & Non-implanted ears & $\begin{array}{l}\text { Preoperative non-implanted and postop- } \\
\text { erative implanted ears }\end{array}$ & Implanted ears & Implanted ears \\
\hline Group & 1 & 2 & 3 & 3 \\
\hline Patients & 20 & 20 & 10 & 10 \\
\hline Number of test series & 2 & 2 & 2 & 2 \\
\hline Test series & $\mathrm{CDL}_{\mathrm{OC}}(\mathrm{mm})$ & $\mathrm{CDL}_{\mathrm{OC}}(\mathrm{mm})$ & $\mathrm{CDL}_{\mathrm{OC}}(\mathrm{mm})$ & $\operatorname{IED}(\mathrm{mm})$ \\
\hline \multicolumn{5}{|c|}{ MSCT postoperative $(600 \mu \mathrm{m})$} \\
\hline $\mathrm{ICC}$ & $0.807^{\mathrm{a}}$ & $0.862^{\mathrm{a}}$ & $0.785^{\mathrm{a}}$ & $0.644^{\mathrm{b}}$ \\
\hline $95 \%$-CI & $0.324^{\mathrm{d}}-0.935$ & $0.578^{\mathrm{c}}-0.950$ & $0.336^{\mathrm{d}}-0.942$ & $0.077^{\mathrm{d}}-0.898$ \\
\hline Cronbach's alpha & $0.934^{\mathrm{a}}$ & $0.946^{\mathrm{a}}$ & $0.869^{\mathrm{b}}$ & $0.776^{\mathrm{c}}$ \\
\hline$t$-Test & $0.0011 *$ & $0.0077 *$ & 0.7499 & 0.4706 \\
\hline Mean & 34.55 & 34.29 & 37.59 & 2.55 \\
\hline Range & $31.20-36.95$ & $30.50-37.15$ & $34.35-42.40$ & $2.20-2.81$ \\
\hline $\mathrm{SD}$ & 1.60 & 1.81 & 2.12 & 0.16 \\
\hline $95 \%$-CI & 1.50 & 1.70 & 3.05 & 0.24 \\
\hline \multicolumn{5}{|c|}{ fpVCT postoperative $(466 \mu \mathrm{m})$} \\
\hline ICC & $0.768^{\mathrm{a}}$ & $0.946^{\mathrm{a}}$ & $0.942^{\mathrm{a}}$ & $0.875^{\mathrm{a}}$ \\
\hline $95 \%$-CI & $0.465^{\mathrm{c}}-0.905$ & $0.578^{c}-0.959$ & $0.783^{\mathrm{a}}-0.985$ & $0.568^{\mathrm{c}}-0.968$ \\
\hline Cronbach's alpha & $0.890^{\mathrm{b}}$ & $0.946^{\mathrm{a}}$ & $0.967^{\mathrm{a}}$ & $0.926^{\mathrm{a}}$ \\
\hline$t$-Test & $0.0297 *$ & 0.1211 & 0.9347 & 0.9646 \\
\hline Mean & 34.63 & 36.43 & 37.01 & 2.51 \\
\hline Range & $31.55-37.60$ & $33.55-39.30$ & $34.70-42.00$ & 0.12 \\
\hline SD & 1.47 & 1.67 & 2.06 & $2.23-2.67$ \\
\hline $95 \%-\mathrm{CI}$ & 1.38 & 1.57 & 2.95 & 0.19 \\
\hline \multicolumn{5}{|c|}{ fpVCT $_{\text {SECO }}$ postoperative $(99 \mu \mathrm{m})$} \\
\hline $\mathrm{ICC}$ & $0.926^{\mathrm{a}}$ & $0.904^{\mathrm{a}}$ & $0.961^{\mathrm{a}}$ & $0.936^{\mathrm{a}}$ \\
\hline $95 \%$-CI & $0.823^{\mathrm{a}}-0.970$ & $0.772^{\mathrm{a}}-0.961$ & $0.854^{\mathrm{a}}-0.990$ & $0.765^{\mathrm{a}}-0.984$ \\
\hline Cronbach's alpha & $0.960^{\mathrm{a}}$ & $0.947^{\mathrm{a}}$ & $0.978^{\mathrm{a}}$ & $0.964^{\mathrm{a}}$ \\
\hline$t$-Test & 0.6359 & 0.9782 & 0.6529 & 0.8220 \\
\hline Mean & 35.84 & 36.18 & 36.55 & 2.50 \\
\hline Range & $32.95-38.45$ & $32.90-39.60$ & $34.55-41.40$ & $2.22-2.68$ \\
\hline SD & 1.39 & 1.75 & 2.07 & 0.14 \\
\hline $95 \%$-CI & 1.30 & 1.64 & 2.98 & 0.21 \\
\hline
\end{tabular}

Overall comparison of intraobserver variability and statistical data of $\mathrm{CDL}_{\mathrm{OC}}$ measurements of each imaging modality and setting

${ }^{a}$ Excellent-ICC: Cronbach's alpha

${ }^{\mathrm{b}}$ Good-unacceptable 0.000-0.400: unacceptable 0.000-0.700

${ }^{\mathrm{c}}$ Fair-fair 0.400-0.600: fair 0.700-0.800

${ }^{\mathrm{d}}$ Unacceptable—good 0.600-0.750: good 0.800-0.900

*Significant-excellent 0.750-1.000: excellent 0.900-1.000

Group 3: comparison of $\mathrm{CDL}_{\mathrm{OC}}$ in cochleae with an inserted electrode and evaluation of the IED by using MSCT, fpVCT and $\mathrm{fpVCT}_{\mathrm{SECO}}$

This investigation was performed in cases with an MSCT and fpVCT scan with an inserted electrode. The mean value for $\mathrm{CDL}_{\mathrm{OC}}$ was $37.59 \mathrm{~mm}$ (range: $34.35-42.40 \mathrm{~mm}$, SD: $2.12 \mathrm{~mm}$ ) using MSCT. Assessing fpVCT, it was $37.01 \mathrm{~mm}$ (range: 34.70-42.00 mm, SD: $2.06 \mathrm{~mm}$ ).

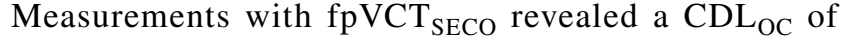
$36.55 \mathrm{~mm}$ (range: $34.55-41.40 \mathrm{~mm}$, SD: $2.07 \mathrm{~mm}$ ) (Fig. 5A). All values demonstrated above did not differ significantly between the different imaging modalities.

For $\mathrm{CDL}_{\mathrm{OC}}$, no significant differences were found within the two test series and ICC was consistently ranked as excellent for all imaging modalities. CA was stated excellent for fpVCT and fpVCT $\mathrm{SECO}_{\mathrm{S}}$ but just good for MSCT. The lower limit of the CI was unacceptable for 

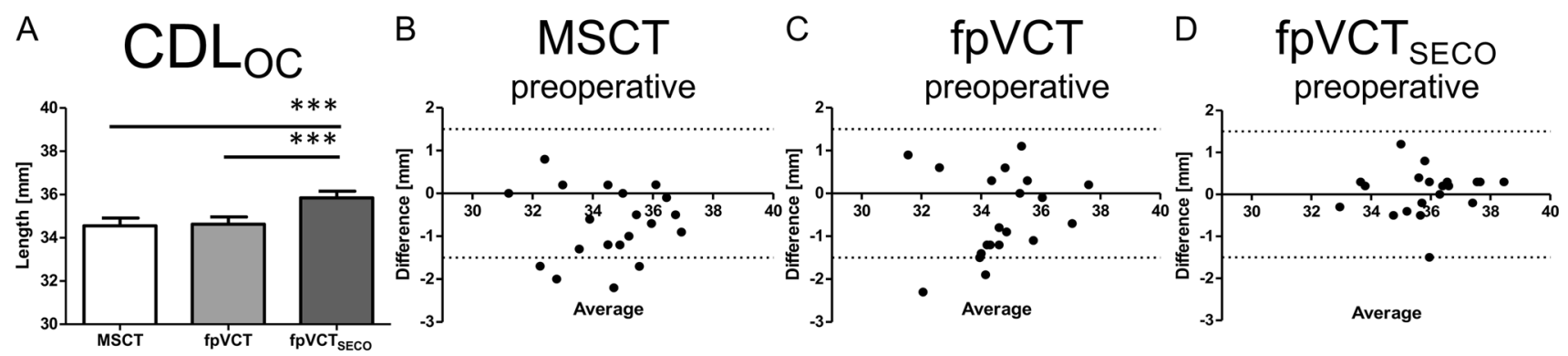

Fig. 3 Analysis of non-implanted ears with comparison of different radiological settings and modalities in a clinical setting (Group 1). Bar shows absolute values of measurements of the $\mathrm{CDL}_{\mathrm{OC}}$ based on MSCT, fpVCT and $\mathrm{fpVCT}_{\text {SECO }}(\mathbf{A})$. Bland-Altman plots were constructed to visualize discrepancies within the two test series of the various imaging settings and modalities (B-D). According to Koch et al. [7], a clinically acceptable deviation of $\pm 1.5 \mathrm{~mm}$ was assumed analyzing $\mathrm{CDL}_{\mathrm{OC}}$. Differences between the cohorts are indicated as significant, ${ }^{* * *} p \leq 0.001$. MSCT: multislice computed tomography, fpVCT: flat-panel volume computed tomography, fpVCT $\mathrm{SECO}_{\text {: }} \mathrm{fpVCT}$ secondary reconstruction
A
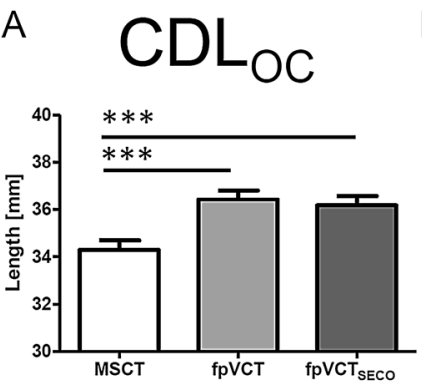

B

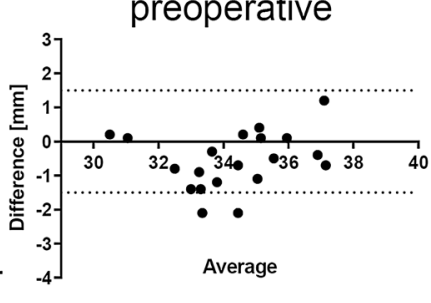

C

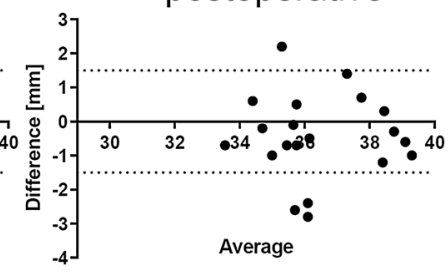

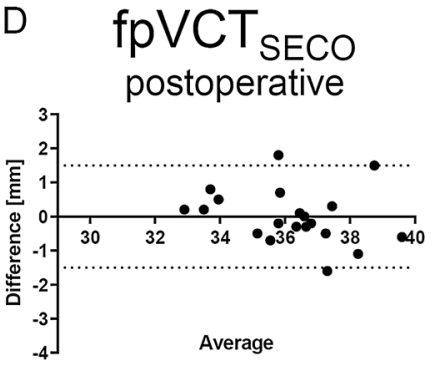

Fig. 4 Analysis of preoperative non-implanted and postoperative implanted ears (Group 2). Bar shows absolute mean values of measurements of $\mathrm{CDL}_{\mathrm{OC}}$ based on MSCT, fpVCT and fpVCT (A). Bland-Altman plots were constructed to visualize discrepancies within the two test series of the various imaging settings and modalities (B-D). According to Koch et al. [7], a clinically acceptable deviation of $\pm 1.5 \mathrm{~mm}$ was assumed analyzing $\mathrm{CDL}_{\mathrm{OC}}$. Notably,

MSCT, while it was excellent for fpVCT and $\mathrm{fpVCT}_{\mathrm{SECO}}$ (Table 2).

To demonstrate a clinically arguable zone, corresponding Bland-Altman-Plots for $\mathrm{CDL}_{\mathrm{OC}}$ were created. For MSCT, 2 clinically unacceptable deviations became apparent (Fig. 5B). For fpVCT, no deviances were observed

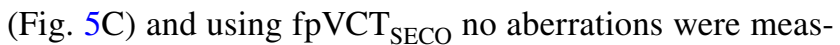
ured (Fig. 5D).

Furthermore, for the purpose of evaluating the accuracy of the determination of electrode contact positions in the different imaging modalities, distances between every single electrode (IED) of the implant were extracted from the otological planning software. A statistical workup of the mean was not performed since different electrodes in different patients have been used. Therefore, a comparison of the three imaging modalities by ICC was carried out. No significant difference was found within the two test series. ICC was good and CA fair for MSCT. In contrast,
MSCT-measurements were done preoperatively without inserted electrode and $\mathrm{fpVCT} / \mathrm{fpVCT}_{\mathrm{SECO}}$ measurements postoperatively. Differences between the different cohorts are indicated as significant, $* * * p \leq 0.001$. MSCT: multislice computed tomography, fpVCT: flatpanel volume computed tomography, fpVCT $\mathrm{SECO}_{\mathrm{SpVCT}}$ secondary reconstruction

the same parameters were excellent when using fpVCT and $\mathrm{fpVCT}_{\text {SECO }}$ (Table 2). The corresponding Bland-AltmanPlots demonstrate four clinically unacceptable deviations for MSCT, two clinically unacceptable aberrations for fpVCT and one clinically unacceptable value for fpVCT $\mathrm{SECO}_{\mathrm{S}}$ (Fig. 5E-G).

\section{Discussion}

In the field of cochlear implantation there is a growing interest in determining the cochlear anatomy and the intracochlear position of an implanted electrode, as it is assumed that an anatomically optimal location of the electrode can lead to a better hearing outcome after surgery [35]. For the preoperative planning and the postoperative position control, new high-resolution imaging techniques as well as newly developed otological planning softwares can be used. In order to 


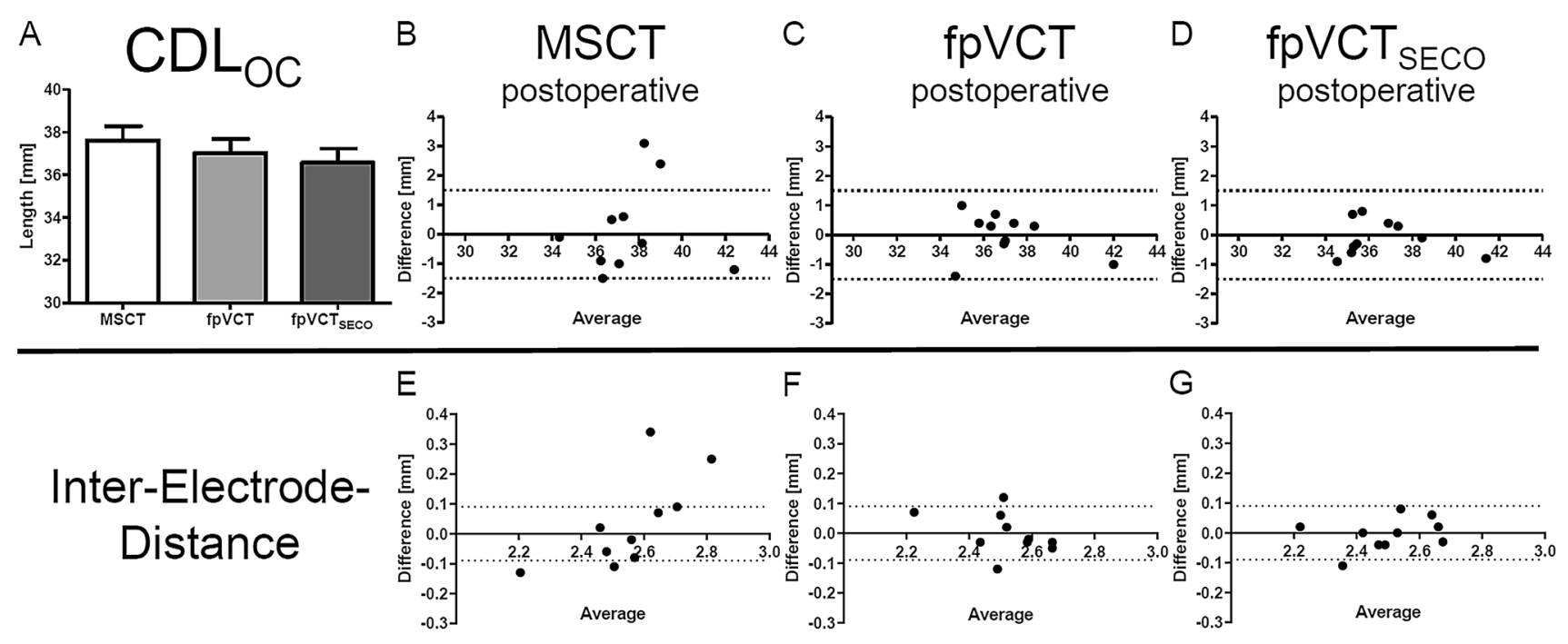

Fig. 5 Analysis of implanted ears (Group 3). Bars shows absolute values of measurements of $\mathrm{CDL}_{\mathrm{OC}}$ based on MSCT, fpVCT and $\mathrm{fpVCT}_{\mathrm{SECO}}$ (A). Bland-Altman plots were constructed to visualize discrepancies within the two test series of the various imaging settings and modalities (B-D). According to Koch et al. a clinically acceptable error of $\pm 1.5 \mathrm{~mm}$ was assumed analysing $\mathrm{CDL}_{\mathrm{OC}}$. Moreover, Bland-Altman plots of $\operatorname{MSCT}(\mathbf{E}), \operatorname{fpVCT}(\mathbf{F})$ and

evaluate whether fpVCT and its secondary reconstruction ( $\mathrm{fpVCT}_{\mathrm{SECO}}$ ) contributes to anatomically based cochlear implantation compared to the conventionally used MSCT, data of the different imaging modalities were analyzed using a newly developed otological planning software in a clinical setting.

The three different imaging modalities were compared measuring the clinically most important parameter $\mathrm{CDL}_{\mathrm{OC}}$. The comparison of MSCT and fpVCT using raw data stacks with similar slice thicknesses revealed only moderate clinical discrepancies. In contrast, clinical relevant differences were seen, when compared to $\mathrm{fpVCT}_{\mathrm{SECO}}$ with low slice thickness, which was the only one that was categorized as excellent in all clinical settings, including postoperative scans with an implanted electrode. Moreover, even the lower limits of the 95\%-CI were consistently ranked as excellent. In comparison to MSCT, where unacceptable deviations in non-implanted ears occurred (20\% in Group 1 (Fig. 3B) and $10 \%$ in Group 2 (Fig. 4B)), there were no clinically unacceptable deviations measuring $\mathrm{CDL}_{\mathrm{OC}}$-values using fpVCT $\mathrm{SECO}_{\mathrm{S}}$ (Fig. 3D). Moreover, in implanted ears (Group 3), there were no divergencies using $\mathrm{fpVCT}_{\mathrm{SECO}}$ (Fig. 5D) compared to deviations in $20 \%$ of the cases using MSCT (Fig. 5B). These results indicate low intra-variability for fp $\mathrm{VCT}_{\mathrm{SECO}}$ measuring $\mathrm{CDL}_{\mathrm{OC}}$ and thus good clinical applicability. This is in accordance with Rathgeb et al., who was among the first to evaluate a good clinical observer variability of the planning software [27]. FpVCT without secondary reconstruction is considered a precise method for assessing the parameters
$\mathrm{fpVCT}_{\mathrm{SECO}}(\mathbf{G})$ were constructed to demonstrate variations within the two test series localizing the IED in postoperative analysed ears. Derived from Koch et al. a clinically acceptable error was calculated with $\pm 0.09 \mathrm{~mm}$ for IED. MSCT: multi-slice computed tomography, fpVCT: flat-panel volume computer-tomography, $\mathrm{fpVCT}_{\mathrm{SECO}}$ : fpVCT secondary reconstruction

of the inner ear with the same or even less radiation dose than conventional methods $[18,19]$. This might reduce the risk of radiogenic damage in the long term $[36,37]$ while increasing diagnostic image quality $[18,19,22]$. The option of generating secondary reconstructions limits the need for further radiation exposure, while the image quality is even more greatly improved. Indeed, the use of $\mathrm{fpVCT}_{\mathrm{SECO}}$ in this study, revealed the above mentioned advantages, in addition to the obvious reduced metal artifacts [20,21]. The demonstrated results are in accordance with recently published data on measurements of $\mathrm{CDL}_{\mathrm{OC}}$ using $\mathrm{fpVCT}_{\mathrm{SECO}}$ in temporal bone specimen [24] using multi-planar reconstructions [38]. This might be well explained by the higher resolution of fpVCT $_{\text {SECO }}$ with a slice thickness of $99 \mu \mathrm{m}$ in comparison to the other image qualities. Summarized, the findings of this study implicate that the application of $\mathrm{fpVCT}_{\mathrm{SECO}}$ facilitates the measurement of the $\mathrm{CDL}_{\mathrm{OC}}$ in clinical imaging and makes them more reproducible in comparison to MSCT using this otological planning software.

The mean values of all measurements, depicted in Fig. 3A and Fig. 4A (regardless with or without implanted electrode) for the $\mathrm{CDL}_{\mathrm{OC}}$ using $\mathrm{fpVCT}_{\mathrm{SECO}}$, were $36.14 \mathrm{~mm}$ and differed significantly between measurements with MSCT $(34.55 \mathrm{~mm})$ and fpVCT $(35.66 \mathrm{~mm})$. That is in contrast to studies on measurements of $\mathrm{CDL}_{\mathrm{OC}}$ using the corresponding software. The authors described a shorter mean length for $\mathrm{CDL}_{\mathrm{OC}}$ with $32.91 \mathrm{~mm}$ [39] and $32.84 \mathrm{~mm}$ [29]. This may be explained by the fact that only conventional MSCT was used. In addition, as the exact version of the software was 
not mentioned in these publications, it might be possible that older versions have been used that did not include the hook region yet in the equation as it was in Version 2 of the software in this study. Moreover, it was suggested that any effect of slice thickness on the CDL measurement is likely rather small. However, it could not be ruled out the possibility that variation in other parameters affecting CT quality could result in greater variability in CDL estimates as this present study has now confirmed [29]. A systematic error was described in recent studies when the points at the lateral wall are placed more medially. This occurs mainly in scans with lower resolution than in high-resolution scans of micro-CT or pictures of histological sections $[9,10]$. This induces shorter values of cochlear parameters. This phenomenon might interestingly also explain why the values measured by MSCT with implanted electrodes, as depicted in Fig. 5A-C, are not even more significantly different and even slightly higher than those measured with fpVCT $\mathrm{VECO}_{\mathrm{SE}}$. Due to the larger artifacts of the electrodes in MSCT, the points marking the lateral wall might be set more laterally than in the true anatomical set, responsible for the discrepancies in different parameters. Therefore, clinical analyses using fpVCT $\mathrm{SECO}_{\mathrm{S}}$ probably represents the true length, since assessments with micro-fpVCT and micro-CT in temporal bone specimens have shown no significant different CDL at the lateral wall values up to over $40 \mathrm{~mm}$ [13, 24], which corresponds to a $\mathrm{CDL}_{\mathrm{OC}}$ of about $35 \mathrm{~mm}$. In line with this, in other studies, shorter CDL values have been reported in clinical modalities $[8,13]$. Based on these and the presented findings, it should be carefully considered whether it might be better to use longer electrodes than currently assumed for covering the correct $\mathrm{CDL}_{\mathrm{OC}}$, when measured by MSCT or other low-resolution images. This might also result in even more accurate predictions for preoperative angular insertion depths, some of which have already been calculated with the planning software [27].

In order to verify the postoperative location of the implant, IED was computed from the data generated in the otological planning software. It was analyzed which imaging modality had the highest accuracy to detect the IED of $2.1 \mathrm{~mm}$ of the FLEX ${ }^{28}$-electrode. Major differences between MSCT and fpVCT $\mathrm{PECO}_{\text {}}$ were observed. Regarding the reproducibility, MSCT was categorized as good, whereas $\mathrm{fpVCT}_{\mathrm{SECO}}$ as excellent. The differences become even clearer, when focusing on the lower limit of the 95\%-CI interval, where MSCT was unacceptable, compared to excellent for fpVCT $\mathrm{fECO}_{\mathrm{SE}}$. Moreover, the presented study revealed that MSCT showed clinically unacceptable deviations in $40 \%$ of the cases (4/10) (Fig. 5E), while using fpVCT $\mathrm{SECO}_{\mathrm{SE}}$, there was only one clinically unacceptable value (10\%) (Fig. 5G). To the best of our knowledge, up to date, this is the first study presenting the IED measured in the used otological planning software. However, in several studies, it was shown that fpVCT is very appropriate for postoperative examination following cochlear implantation, in particular, to determine the final position of the electrode arrays [22, $23,40]$, but in none of these publications the intra-electrode variables were measured. The increased clinically unacceptable errors using MSCT in this study are presumably due to radiological artifacts. Indeed, it has already been shown that the real diameter of the electrode is half in comparison to the radiological one in CBCT [41]. Even rather, a study reported that single electrode contacts are only visible in fpVCT and not in MSCT [22]. This may be of clinical relevance, as it is assumed that a regular tonotopic stimulation of the cochlea by the electrode could lead to improved hearing performance and a better speech perception [42-44]. Therefore, the wide variation of the measurements using MSCT could lead to an incorrect calculation of frequency mapping. Jiam et al. demonstrated that based on $\mathrm{fpVCT}_{\text {SECO }}$ imaging findings, $83 \%$ of the electrode contacts, in which standardized frequency maps were used, might be improved by reprogramming and concluded that individual pitch mapping should be performed [35]. These pitch maps would be even more accurate if the particular electrode position was located as precisely as possible.

It needs to be mentioned that only one electrode type from one implant-firm was used for measuring IED. This is due to the use of the otological planning software, which only allows the use of the manufacture's electrodes. However, it is known that certain electrodes are more prone to generate artefacts, which are believed to depend on the thickness and material of the metal [45]. Therefore, we cannot exclude that the problems of MSCT measuring the IED may be more a problem of the electrode rather than of the modality.

One potential limitation of this study is the sample size concerning pre- and postoperative measurements. In addition, the study has the limitation to observe only intraobserver variability, but low interobserver variability in the use of this otologic planning software has been shown before [27-29]. We also cannot rule out a possible influence of the investigator's training curve. However, since there was a blinded and randomized sequence not only of the patient data but also of the imaging modalities, such an effect would affect all modalities.

\section{Conclusion}

The results of the presented study suggest that the combination of $\mathrm{fpVCT}_{\mathrm{SECO}}$ and otological planning software will enable further progress in the development of an anatomically based cochlear implantation. It might be beneficial to perform the preoperative planning on cochlear implantation regarding the correct electrode selection with $\mathrm{fpVCT}_{\mathrm{SECO}}$ utilizing the otological planning software. Furthermore, 
postoperative control of the IED with $\mathrm{fpVCT}_{\mathrm{SECO}}$ will enhance accuracy of creating individual pitch maps through the software. This might further improve the exact determination of cochlear anatomy and refine postoperative frequency mapping for a better hearing outcome.

Acknowledgements The authors thank the team of the Comprehensive Hearing Center at the University of Wuerzburg for extensive help.

Author contributions FTMG performed the analysis, wrote, and edited the paper. LI supported the statistical evaluation and created secondary reconstructions. PS, JV, JT, AK, RH edited the paper. TN created secondary reconstructions and edited the paper. KR conceived and designed the study as well as wrote the manuscript.

Funding Open Access funding enabled and organized by Projekt DEAL.

Data availability The data of the measurements generated in this study are available upon reasonable request from the corresponding author.

\section{Declarations}

Conflict of interest To the best of the authors' knowledge, no conflicts of interest exist.

Ethical approval The anonymous retrospective data analysis was performed in concordance with the Declaration of Helsinki and approved by the local ethic committee of the University of Würzburg (2019020401).

Consent for publication All authors give their consent for publication.

Open Access This article is licensed under a Creative Commons Attribution 4.0 International License, which permits use, sharing, adaptation, distribution and reproduction in any medium or format, as long as you give appropriate credit to the original author(s) and the source, provide a link to the Creative Commons licence, and indicate if changes were made. The images or other third party material in this article are included in the article's Creative Commons licence, unless indicated otherwise in a credit line to the material. If material is not included in the article's Creative Commons licence and your intended use is not permitted by statutory regulation or exceeds the permitted use, you will need to obtain permission directly from the copyright holder. To view a copy of this licence, visit http://creativecommons.org/licenses/by/4.0/.

\section{References}

1. Buchner A, Illg A, Majdani O, Lenarz T (2017) Investigation of the effect of cochlear implant electrode length on speech comprehension in quiet and noise compared with the results with users of electro-acoustic-stimulation, a retrospective analysis. PLoS ONE 12(5):e0174900. https://doi.org/10.1371/journal.pone.0174900

2. Hochmair I, Arnold W, Nopp P, Jolly C, Muller J, Roland P (2003) Deep electrode insertion in cochlear implants: apical morphology, electrodes and speech perception results. Acta Otolaryngol 123(5):612-617

3. O'Connell BP, Cakir A, Hunter JB, Francis DO, Noble JH, Labadie RF, Zuniga G, Dawant BM, Rivas A, Wanna GB (2016) Electrode location and angular insertion depth are predictors of audiologic outcomes in cochlear implantation. Otol Neurotol 37(8):1016-1023. https://doi.org/10.1097/mao.0000000000001125

4. O'Connell BP, Hunter JB, Haynes DS, Holder JT, Dedmon MM, Noble JH, Dawant BM, Wanna GB (2017) Insertion depth impacts speech perception and hearing preservation for lateral wall electrodes. Laryngoscope 127(10):2352-2357. https://doi.org/10.1002/lary.26467

5. Escude B, James C, Deguine O, Cochard N, Eter E, Fraysse B (2006) The size of the cochlea and predictions of insertion depth angles for cochlear implant electrodes. Audiol Neurootol 11(Suppl 1):27-33. https:// doi.org/10.1159/000095611

6. Helpard LW, Rohani SA, Ladak HM, Agrawal SK (2020) Evaluation of cochlear duct length measurements from a 3D analytical cochlear model using synchrotron radiation phase-contrast imaging. Otol Neurotol 41(1):e21-e27. https://doi.org/10.1097/mao.0000000000002420

7. Koch RW, Elfarnawany M, Zhu N, Ladak HM, Agrawal SK (2017) Evaluation of cochlear duct length computations using synchrotron radiation phase-contrast imaging. Otol Neurotol 38(6):e92-e99. https://doi.org/ 10.1097/MAO.0000000000001410

8. Schurzig D, Timm ME, Batsoulis C, John S, Lenarz T (2018) Analysis of different approaches for clinical cochlear coverage evaluation after cochlear implantation. Otol Neurotol 39(8):e642-e650. https://doi.org/ 10.1097/MAO.0000000000001904

9. Schurzig D, Timm ME, Batsoulis C, Salcher R, Sieber D, Jolly C, Lenarz T, Zoka-Assadi M (2018) A novel method for clinical cochlear duct length estimation toward patient-specific cochlear implant selection. OTO Open 2(4):2473974X18800238. https://doi.org/10.1177/24739 $74 X 18800238$

10. Schurzig D, Timm ME, Lexow GJ, Majdani O, Lenarz T, Rau TS (2018) Cochlear helix and duct length identification - evaluation of different curve fitting techniques. Cochlear Implants Int 19(5):268-283. https://doi.org/10.1080/14670100.2018.1460025

11. van den Boogert T, van Hoof M, Handschuh S, Glueckert R, Guinand N, Guyot JP, Kingma H, Perez-Fornos A, Seppen B, Johnson Chacko L, Schrott-Fischer A, van de Berg R (2018) Optimization of 3D-visualization of micro-anatomical structures of the human inner ear in osmium tetroxide contrast enhanced micro-CT scans. Front Neuroanat 12:41. https://doi.org/10.3389/fnana.2018.00041

12. Vu TH, Perazzini C, Puechmaille M, Bachy A, Mulliez A, Boyer L, Mom T, Gabrillargues J (2019) CT-scan contouring technique allows for direct and reliable measurements of the cochlear duct length: implication in cochlear implantation with straight electrode-arrays. Eur Arch Otorhinolaryngol 276(8):2135-2140. https://doi.org/10.1007/ s00405-019-05432-6

13. Wuerfel W, Burke W, Lenarz T, Kraemer R (2015) Cochlear length determination in temporal bone specimens using histological serialmicro grinding imaging, micro computed tomography and flat-panel volumetric com-puted tomography. Otolaryngol J 5:39-59

14. Wurfel W, Lanfermann H, Lenarz T, Majdani O (2014) Cochlear length determination using cone beam computed tomography in a clinical setting. Hear Res 316:65-72. https://doi.org/10.1016/j.heares.2014.07. 013

15. Gupta R, Cheung AC, Bartling SH, Lisauskas J, Grasruck M, Leidecker C, Schmidt B, Flohr T, Brady TJ (2008) Flat-panel volume CT: fundamental principles, technology, and applications. Radiographics 28(7):2009-2022. https://doi.org/10.1148/rg.287085004

16. Gupta R, Bartling SH, Basu SK, Ross WR, Becker H, Pfoh A, Brady T, Curtin HD (2004) Experimental flat-panel high-spatialresolution volume $\mathrm{CT}$ of the temporal bone. AJNR Am J Neuroradiol 25(8):1417-1424

17. Rotter N, Schmitz B, Sommer F, Rohrer S, Schuler PJ, Bischof F, Scheithauer MO, Hoffmann TK (2017) First use of flat-panel computed tomography during cochlear implant surgery: perspectives for the use of advanced therapies in cochlear implantation. HNO 65(1):61-65. https://doi.org/10.1007/s00106-016-0213-z

18. Conte G, Scola E, Calloni S, Brambilla R, Campoleoni M, Lombardi L, Di Berardino F, Zanetti D, Gaini LM, Triulzi F, Sina C 
(2017) Flat panel angiography in the cross-sectional imaging of the temporal bone: assessment of image quality and radiation dose compared with a 64-section multisection CT scanner. AJNR Am J Neuroradiol 38(10):1998-2002. https://doi.org/10.3174/ajnr. A5302

19. Piergallini L, Scola E, Tuscano B, Brambilla R, Campoleoni M, Raimondi G, Lombardi L, Di Berardino F, Zanetti D, Sina C, Triulzi F, Conte G (2018) Flat-panel CT versus 128-slice CT in temporal bone imaging: assessment of image quality and radiation dose. Eur J Radiol 106:106-113. https://doi.org/10.1016/j.ejrad. 2018.07.013

20. Arweiler-Harbeck D, Monninghoff C, Greve J, Hoffmann T, Goricke S, Arnolds J, Theysohn N, Gollner U, Lang S, Forsting M, Schlamann M (2012) Imaging of electrode position after cochlear implantation with flat panel CT. ISRN Otolaryngol 2012:728205. https://doi.org/10.5402/2012/728205

21. Zeitler DM, Wang KH, Prasad RS, Wang EY, Roland JT (2011) Flat-panel computed tomography versus multislice computed tomography to evaluate cochlear implant positioning. Cochlear Implants Int 12(4):216-222. https://doi.org/10.1179/146701011X 12962268235742

22. Struffert T, Hertel V, Kyriakou Y, Krause J, Engelhorn T, Schick B, Iro H, Hornung J, Doerfler A (2010) Imaging of cochlear implant electrode array with flat-detector $\mathrm{CT}$ and conventional multislice CT: comparison of image quality and radiation dose. Acta Otolaryngol 130(4):443-452. https://doi.org/10.3109/00016 480903292700

23. Pearl MS, Roy A, Limb CJ (2014) High-resolution secondary reconstructions with the use of flat panel $\mathrm{CT}$ in the clinical assessment of patients with cochlear implants. AJNR Am J Neuroradiol 35(6):1202-1208. https://doi.org/10.3174/ajnr.A3814

24. Schendzielorz P, Ilgen L, Mueller-Graff T, Noyalet L, Volker J, Taeger J, Hagen R, Neun T, Zabler S, Althoff D, Rak K (2021) Precise evaluation of the cochlear duct length by flat-panel volume computed tomography (fpVCT)-implication of secondary reconstructions. Otol Neurotol 42(3):e294-e303. https://doi.org/ 10.1097/MAO.0000000000002951

25. Ping L, Barazzetti L, Chandran V, Gavaghan K, Weber S, Gerber N, Reyes M (2015) Facial nerve image enhancement from CBCT using supervised learning technique. Conf Proc IEEE Eng Med Biol Soc 2015:2964-2967. https://doi.org/10.1109/EMBC.2015. 7319014

26. Lovato A, de Filippis C (2019) Utility of OTOPLAN reconstructed images for surgical planning of cochlear implantation in a case of post-meningitis ossification. Otolo Neurotolo 40(1):e60 e61. https://doi.org/10.1097/MAO.0000000000002079

27. Rathgeb C, Dematte M, Yacoub A, Anschuetz L, Wagner F, Mantokoudis G, Caversaccio M, Wimmer W (2019) Clinical applicability of a preoperative angular insertion depth prediction method for cochlear implantation. Otol Neurotol 40(8):1011-1017. https:// doi.org/10.1097/MAO.0000000000002304

28. Mertens G, Van Rompaey V, Van de Heyning P, Gorris E, Topsakal V (2020) Prediction of the cochlear implant electrode insertion depth: clinical applicability of two analytical cochlear models. Sci Rep 10(1):3340. https://doi.org/10.1038/s41598-020-58648-6

29. Cooperman SP, Aaron KA, Fouad A, Tran E, Blevins NH, Fitzgerald MB (2021) Assessment of inter- and intra-rater reliability of tablet-based software to measure cochlear duct length. Otol Neurotol. https://doi.org/10.1097/MAO.0000000000003015

30. George-Jones NA, Tolisano AM, Kutz JW Jr, Isaacson B, Hunter JB (2020) Comparing cochlear duct lengths between CT and MR images using an otological surgical planning software. Otol Neurotol 41(9):e1118-e1121. https://doi.org/10.1097/MAO.00000 00000002777
31. Xu J, Xu SA, Cohen LT, Clark GM (2000) Cochlear view: postoperative radiography for cochlear implantation. Am J Otol 21(1):49-56

32. Verbist BM, Skinner MW, Cohen LT, Leake PA, James C, Boëx C, Holden TA, Finley CC, Roland PS, Roland JT Jr, Haller M, Patrick JF, Jolly CN, Faltys MA, Briaire JJ, Frijns JHM (2010) Consensus panel on a cochlear coordinate system applicable in histological, physiological and radiological studies of the human cochlea. Otol Neurotol 31(5):722-730

33. Wirtz M (2004) Determining the quality of rater judgements using intraclass correlation, and enhancing rater judgements. Rehabilitation 43(6):384-389. https://doi.org/10.1055/s-2003-814935

34. Cicchetti DV (1994) Guidelines, criteria, and rules of thumb for evaluating normed and standardized assessment instruments in psychology. Psychol Assess 6:284-290

35. Jiam NT, Pearl MS, Carver C, Limb CJ (2016) Flat-panel CT imaging for individualized pitch mapping in cochlear implant users. Otol Neurotol 37(6):672-679. https://doi.org/10.1097/ MAO.0000000000001060

36. Pearce MS, Salotti JA, Little MP, McHugh K, Lee C, Kim KP, Howe NL, Ronckers CM, Rajaraman P, Sir Craft AW, Parker L, Berrington de Gonzalez A (2012) Radiation exposure from CT scans in childhood and subsequent risk of leukaemia and brain tumours: a retrospective cohort study. Lancet 380(9840):499-505. https://doi.org/10.1016/S0140-6736(12)60815-0

37. Rehani MM, Berry M (2000) Radiation doses in computed tomography. The increasing doses of radiation need to be controlled. BMJ 320(7235):593-594

38. Würfel W, Lanfermann H, Lenarz T, Majdani O (2014) Cochlear length determination using cone beam computed tomography in a clinical setting. Hear Res 316:65-72. https://doi.org/10.1016/j. heares.2014.07.013

39. Khurayzi T, Almuhawas F, Sanosi A (2020) Direct measurement of cochlear parameters for automatic calculation of the cochlear duct length. Ann Saudi Med 40(3):212-218. https://doi.org/10. 5144/0256-4947.2020.218

40. Franke-Trieger A, Mürbe D (2015) Estimation of insertion depth angle based on cochlea diameter and linear insertion depth: a prediction tool for the CI422. Eur Arch Otorhinolaryngol 272(11):3193-3199. https://doi.org/10.1007/s00405-014-3352-4

41. Guldner C, Wiegand S, Weiss R, Bien S, Sesterhenn A, Teymoortash A, Diogo I (2012) Artifacts of the electrode in cochlea implantation and limits in analysis of deep insertion in cone beam tomography (CBT). Eur Arch Otorhinolaryngol 269(3):767-772. https://doi.org/10.1007/s00405-011-1719-3

42. Greenwood DD (1990) A cochlear frequency-position function for several species-29 years later. J Acoust Soc Am 87(6):2592-2605. https://doi.org/10.1121/1.399052

43. Landsberger DM, Mertens G, Punte AK, Van De Heyning P (2014) Perceptual changes in place of stimulation with long cochlear implant electrode arrays. J Acoust Soc Am 135(2):EL75EL81. https://doi.org/10.1121/1.4862875

44. Stakhovskaya O, Sridhar D, Bonham BH, Leake PA (2007) Frequency map for the human cochlear spiral ganglion: implications for cochlear implants. J Assoc Res Otolaryngol 8(2):220-233. https://doi.org/10.1007/s10162-007-0076-9

45. Bamberg F, Dierks A, Nikolaou K, Reiser MF, Becker CR, Johnson TR (2011) Metal artifact reduction by dual energy computed tomography using monoenergetic extrapolation. Eur Radiol 21(7):1424-1429. https://doi.org/10.1007/s00330-011-2062-1

Publisher's Note Springer Nature remains neutral with regard to jurisdictional claims in published maps and institutional affiliations. 